Down Syndrome Research and Practice Vol. 6, No. 1, pp 1 - 18

(C) The Down Syndrome Educational Trust

Printed in Great Britain. All Rights Reserved.

ISSN: 0968-7912 (1999) 6:1

\title{
THE SOCIAL DEVELOPMENT OF CHILDREN WITH SEVERE LEARNING DIFFICULTIES: A CASE STUDY OF AN INCLUSIVE EDUCATION INITIATIVE BETWEEN TWO PRIMARY SCHOOLS IN OXFORDSHIRE, UK.
}

\author{
Denise Dew-Hughes and Sonia Blandford \\ Oxford Brooks University, UK
}

\begin{abstract}
This case study of primary age children in two linked Oxfordshire schools investigated the contribution of staff attitudes and practices to inequalities in education, and contrasted the socialisation of children with similar learning difficulties in different educational placements.

Participant observation of a group of children and carers in a special school suggested areas of more rigorous inquiry. Structured observations compared this group with a matched sample of children with similar learning difficulties in a mainstream setting. Staff on both sites were invited to comment on findings arising from analysed data in order to identify attitudes and policies which might account for the observed differences in practice.

The study was engendered by experience of differences arising from educational placement. The theoretical stance arose through reviewing previous work, predominantly the debate on inclusive education, and the wider issues of human rights and equal opportunities embedded in the social development of people with disabilities. The theoretical framework underpinning this study is established in some depth.

The project was designed to investigate issues of the wider social perspective, by conducting a micro-study of one model of educational inclusion whose outcomes have direct relevance to those issues.
\end{abstract}

Keywords: social development, inclusive education, severe learning difficulties, educational outcomes, classroom practice, equality of opportunity

\section{Purpose of Research}

The process of integrated or inclusive education for children with severe learning difficulties continues to be a forum for ongoing debate. The issue of integration is far from either being settled ideologically or translated into uniform examples of sound policy, procedures and practice.

The issues of equality of opportunity, human rights, of access to a broad-based and relevant education suited differentially to individual needs, celebrating individual contributions and empowering all young people to play a selfdetermined role in the wider social world, are prescribed by each Local Education Authority (LEA) in England and Wales in their curriculum statements and need no further description here. Prescriptive policy statements for pupils with special educational needs are also available in all schools, as required for good practice and inspection. Such documents provide definitions and guidelines for the regulation of standards.

Many schools have developed their provision of inclusive education over a number of years. Some projects are well-documented (Dew-Hughes, 1983, 1984; Southgate, 1992) while others remain unsung local initiatives; many are of long standing and all have been informed by the 
proposals of the Warnock Report (1978) and positively promoted by the LEA. Oxfordshire LEA, in 'middle England' is recognised nationally for its good practice in this area.

\section{TTA Teacher Research Initiative}

In 1996, the Teacher Training Agency advertised its pilot scheme of funding teachers to carry out small-scale, classroom-based research projects investigating their own and other teachers' practice. The projects focused on improving professional standards in teaching by involving practitioners in active research, making research findings more accessible, and generally raising awareness of what the process and outcomes of research can add to classroom practice.

\section{The Research Project}

The lack of independence and social know-how is not due to the original impairment, but rather to the lack of sufficient socialisation (Centre for Educational Research and Innovation, 1988).

For many children in special schools this social development is a central aim of their education (OFSTED Handbook, 1995).

The range of needs presented by children with severe learning difficulties results in a wide variation of practice even within the most solid projects. Good practice and provision require regular monitoring of well-established inclusion projects, especially during a period of change prompted by outside factors. Wilson (1993) suggests that well-established schemes are vulnerable to factors such as staff changes or differences in perception of the decision-makers.

The research was set within a process of change. It formed part of the on-going monitoring of a long-established parallel link between a school for children with severe learning difficulties and a primary mainstream school. The small-scale study took place at a junction where the special school was effecting amalgamation with another special school educating pupils at Key Stages (KS) 3 and 4. It became evident that because of the extended age-range of provision it would be necessary to assess practice at KS 1 and 2 in terms of eventual outcomes.

A further issue influencing the project was the need of Years 4, 5 \& 6's Co-ordinator to establish team guidelines to emphasise the relationship between social development and attitude and/or practice; to consider their effect on educational outcomes in terms of maturity and membership of society at these later Key Stages.

\section{Sample}

Pupils with severe learning difficulties were selected from two schools with a 20-year integration link. The groups were matched for age (Year 3) and educational ability. Most pupils had developmental delay, some had recognised conditions which affected their learning. Included in each group was one boy with Down syndrome; both had good general health and excellent speech and communication skills. Both had a hearing impairment which was assisted by post-aural aids, and access to support from the LEA's Sensory Impairment Service. The group in the special school had few physical disabilities which affected classroom work, and were following programmes of a similar nature to their mainstream peers. The pupils in the mainstream school were on the roll of and supported by special school staff. Each group of six pupils had one teacher and one Learning Support Assistant (LSA). Both sample groups were part of a larger class group which in mainstream was similar to the sample group (children with learning difficulties who were on the mainstream roll) while the special school class covered a wider range of learning difficulties which included children with autism.

The placement of these similarly-affected children on a mainstream or special site was determined by a combination of factors unconnected with their level of learning difficulty. The sample groups were selected because the pupils in them were theoretically interchangeable; placement rather than ability therefore represented the main variable.

\section{Rationale}

Participant observation by one author suggested that youngsters with severe learning difficulties had delayed levels of social development in special schools compared with those included on mainstream sites whose learning difficulties were equally severe. Feedback from staff development sessions conducted by this author, which aimed to establish common practice for the Years 4,5 \& 6 Co-ordinator and eight assistant staff members, indicated a need for a more structured study into elements constituting teaching practices and attitudes. The amalgamation of the special schools raised questions of the social development of pupils across a wider age range, and whether educational outcomes at Key Stage 4 were affected by differences between mainstream and special school practices.

If those aspects of mainstream socialisation which were beneficial to pupils included in mainstream school could be identified and 
transferred to the special site, pupils would benefit from some aspects of inclusive education, even where physical transfer to a mainstream site was not feasible.

It has long been theorised that 'included' pupils learn by imitating peer example and that social development somehow 'rubs off' on them simply by being exposed to it. This would only be the case where staff attitudes and practices were identical on both sites.

\section{Methodology}

To identify in detail the elements of social interaction within the classroom, a series of timed observations was arranged with the sample group in both schools. Each group was observed in the classroom, during play and lunch time activities; timed observations and more general field notes were taken. Following the observations the Head Teacher, Class Teacher and Learning Support Assistant (LSA) for both groups were interviewed with semi-structured, guided conversations which were recorded and analysed. Relevant themes and opinions were drawn from these interviews and compared with the observed activities. In this way it was hoped to determine attitudes by allowing staff to comment on or explain observed practices and events. By inviting comments on analysed data, the staff's interpretations were recorded, rather than the researcher's.

Prior to visiting the schools copies of a written research contract were offered to the adults taking part and the purpose of the project explained. The LSA in each group was interviewed because she carried out many teaching activities. As her training had been provided by the class teacher, she was considered likely to share the same approaches.

\section{Observations}

Five sessions of observation were carried out in each school, pupils being allocated to pre-set categories of activity at five-minute intervals. The first four timed observations were classroom situations, the fifth was a general observation of lunch and play sessions. The four classroom based observations were:

1. academic activity

2. personal interactions

3. teacher and /or LSA interactions with the pupil

4. incidence of independent or unsupervised working

Pre-set activities were recorded on a matrix for each of the six pupils; explanatory field notes were recorded in more detail. Observations were designed to show:

- whether pupils were heavily dependant on adult assistance, or

- could work independently, with a partner or in a small group

- whether pupils preferred the company of adults in recreation time

- whether there were differences in language and behaviour on the two sites

Observations were simplified by the preparation of matrix sheets which allowed for each child's activity to be recorded within one set of parameters per session. Raw data yielded by the sessions allowed eyeball analysis of patterns of events as well as more detailed comparisons of individual children's activity during each onehour session.

Comparisons of matrix charts between the two schools were capable of showing immediate differences in data 'pattern' which could be readily appreciated by staff; these formed the basis for practitioner interviews. The charts provided quick reference and suggested where more detailed analysis involving numbers of recorded incidents might yield further evidence. Explanatory field notes set the context, allowing for those unintentional difficulties or insights which the more rigid system of data recording on the charts could not accommodate. One factor not included on the matrix, that of interruptions by adults entering the classroom and claiming the teacher's attention, was recorded by simple tallying, and became a significant topic for staff interview.

\section{Analysis of Data}

The framework for analysis used was a set of indicators of social maturity readily available to classroom teachers:

- co-operating with a partner or a group

- playing co-operatively during leisure time

- being aware of different adult roles

- reducing reliance on the teacher or LSA

- looking after belongings and equipment

- working independently at a set task

- maintaining appropriate work behaviour to finish a task

- concentrating and avoiding distractions

- choosing activities, food and personal care

Data were analysed by comparison of these indicators for length and frequency, the differences between and occurrence of each factor for both sample groups. The indicators were amalgamated into four broad categories 
- the social maturity of the children

- social relationships with the staff

- attitudes and practices of the staff

- educational outcomes

These formed the basis of interviews, where staff members were invited to comment on observed data in context and to anticipate educational outcomes.

\section{Interviews}

Staff were interviewed with a semi-structured guided conversation which invited comments on the indicators listed above and other issues which elicited their attitudes towards social development and how it might be promoted.

These issues included:

- whether children with learning difficulties were less mature than their peers

- whether this was caused by the disability itself or the way in which they were treated

- if having a mainstream peer group or mainstream placement changed this

- whether teachers expected pupils on special school site to behave younger than mainstream children

- if physical care regimes or low academic ability encouraged teachers to see pupils as less mature than their peers

- whether children confused adult roles, and what might contribute to this

- if social maturity made a difference at point of transfer or leaving school

Recorded interviews were transcribed and analysed using Word 7 with Windows 95.

Comments relating to each of the four categories were colour coded, and using cut-spike-paste procedures, rewritten as new documents each of which considered one category. Views of staff on different sites were not compared ${ }^{1}$, but accumulated comments were examined for common themes and majority opinions. There was an unusual level of agreement among the staff, the greatest being that of the two Head Teachers whose policies overlapped considerably despite wide differences in their daily school practice. Generally, staff showed they were aware of the differences site placement made to social development. Where they had considered the sensitive issue of outcomes at later Key Stages they stressed its importance.

\section{Social Maturity}

All staff believed that children in special schools

- were 'quite a lot less' socially mature than mainstream peers

- became more mature when included in mainstream, responding 'quite dramatically to the behaviour of other children'

- had a flexible curriculum allowing time for extra interpersonal and social skills teaching

Teachers initially said that social immaturity was located in the disability. They amended this by stating that it was caused by a lack of early social interaction. Learning from peers was not enough unless it began 'when children are infants'. All agreed that adult expectations were 'definitely', 'absolutely' a contributing factor, as were the atmosphere and structure of the school. Several declared that they made unconscious assumptions about social maturity which delayed development. All recommended encouraging children to be more self-reliant and take responsibility for their own actions as a move towards maturity:

\section{'treat them age related, and have expectations of their social and academic achievement, because we think we're aiming too low'}

\section{Practices and Attitudes}

All staff interviewed agreed that special schools

- unlike mainstream, had a family atmosphere

- combined the roles of teacher and parent, resulting in some confusion for the child

- treated pupils as if they were less mature and capable than mainstream peers

- treated children closer to their academic than chronological age

- offered few opportunities for independence, self-responsibility, risk-taking or show what 'they are capable of achieving'

- made fewer demands on parents

- had attitudes and practices which affected outcomes as they could be the deciding factor for senior school and post-16 placement.

Reasons for this were given as

- the lower social maturity of pupils on entry

- the lack of peer-group role models

- the influence of Nursery Nurses' practice

- calling staff by first names

- staff being unaware of the children's true capabilities or potential

- over-protectiveness in social situations

- convenience - quicker to help than to wait for children to help themselves

- the constraints of children with more severe difficulties in the same group

Special school staff considered the family atmosphere a bonus - a strong ethos of personal care appealed to parents. Unlike the mainstream staff, they did not consider that it might cause delay in social maturity and independence. They also assumed that social and academic levels were related. 
The mainstream teachers believed that all children wished and had the right to behave like their peers; staff would facilitate this if a child was experiencing difficulties. Having peer groups for constant comparison raised the priority of social development as an educational outcome. They saw the children's social capabilities as outstripping their academic ability.

\section{Social Relationships}

Children in the mainstream school

- had no role confusion, they saw staff as professionals not family, and used titles to address them

- were cuddled if distressed, but 'talking about the problem and helping sort it out' was more usual

On the special school site

- children were cuddled for reasons relating to their social needs 'if they want it, there must be a reason for it' to 'feel that someone really cares about them'

- some were seen as needing 'to have a close relationship with a teacher'

- children were touched all the time although 'part of the staff training should be about how we handle children and is it always necessary'

- staff commented 'we're like their extended family'

The special school staff had not considered that close personal relationships with children could restrict social development; the mainstream staff were extremely sensitive to establishing a professional relationship and valued their distinct role as teachers.

'Whose needs are you satisfying?'

'Would I like someone to do this to my own child... or even to me...

Sometimes in special schools (they) do things to children that they wouldn't like done to themselves or to their own children.'

'Maybe they need (cuddles) in mainstream and don't get it because people have different perceptions of what touching a child is.'

\section{Outcomes}

Some had not given educational outcomes full consideration but those who had were adamant of the importance of social maturity in the following areas:

- choices of senior school or access to employment and further education were particularly important. It has 'quite a lot' of influence on their choice of secondary school and ability to cope - 'it's a HUGE factor'. 'Those who are 'socially and emotionally vulnerable (are) much less easy to transfer successfully' to secondary schools.

- Children who transferred successfully into mainstream secondary schools were more 'socially mature although they may have been slightly less academically able'. 'They can cope... on the social side and ask for help on an academic level'.

- Socially mature young people were 'more likely to find jobs' even if 'academically behind'. 'over the years... it has always (been) a real worry for us'; 'we've never got this right'.

Teachers also commented on other aspects of practices and attitudes:

- professional concerns invited them to treat children closer to their academic ability than chronological age.

- close physical care activities for older children maintain attitudes 'which we've normally left behind with... infants, we still carry that idea of them as babies.'

- different adult roles became blurred by extended care regimes and familial contacts delaying the children's secondary socialisation where distinctions between home and school fall into place. 'I don't think it helps if parents call you by your Christian name... this professional line isn't there.'

- children with SLD included into mainstream schools at whatever age change their social behaviour. 'There's no other factor... they came on by leaps and bounds almost the minute they walked through the door' (of mainstream).

\section{'They've got more choices'}

'If we haven't encouraged them from the earliest opportunity to take responsibility... to learn the hard way, then I don't think we've done them any good service.'

\section{Classroom observation}

Timed and recorded observations (as described above) were carried out during a three-week period in late September, when pupils and teachers had settled into a routine. Observations showed that children differed considerably in some respects depending on site whereas other indicators showed less variety. There were wide varieties in recorded 'pattern'; the mainstream group having a readily observable fixed routine. Most noticeable were factors such as working alone or with a partner and asking for adult help, and these were subjected to closer analysis where frequency and duration were noted and compared. 


\section{Social maturity}

Most noticeable was the duration and frequency of children working co-operatively at a set task in a group or with a partner. Most children on the mainstream site managed several periods of 30 minutes, but in the special school, teacher intervention was usually required after 10 minutes.

Spontaneous interactions between children were rarer in the special school. Most needed direction to work with a (teacher-chosen) partner or group. The mainstream children paired or grouped naturally, choosing different peers for recreational and work activities. There were some highly co-operative interactions, asking each other for help. Three children in the special school and one on the mainstream site exhibited uncooperative behaviour.

Appropriate self-employment between tasks was rare on the special school site, children usually chose solo play with toys, whereas in the mainstream school there were child-determined changes of activity within an agreed academic range after completing a given task.

Opportunities for self-help and independence were almost never offered to the special school children, while the mainstream group had to look after their own belongings and tidy work materials after sessions. Mainstream children were offered choices of activity after finishing given tasks, they chose whether to wear a coat for outdoors whereas special school children's coats were fetched by the staff.

Both groups chose their food at lunch time. Special school children ate lunch with their class group in an appointed seat; the mainstream children ate packed lunches with chosen companions or queued for service from the kitchen hatch.

Playtime on the special site presented few opportunities for organised, interactive or exploratory play, and children were not exposed to risk situations ${ }^{2}$. Mainstream school play areas were more amenable to both active games and sociable chatting. Undirected interactions between children were frequent.

\section{Social Relations with Staff}

On the mainstream site there was a clear teacher-pupil relationship, with formal use of titles. The LSA was more immediate in her relationship, less didactic but still not maternal. Mutual respect was noticeable, and children's permission was requested before inserting their

${ }^{2}$ At the time of this project, the $\mathrm{S}$ playground was not in use. names into the story-time reading. The special school children called everyone by their first name, whether teacher, peer, therapist or visitor. Only the Head and Senior Teachers were referred to as Mrs -.

Almost all the special school children had physical contact with the staff during observations, for comfort, physical care, help with dressing, hand-holding or pats for praise. No mainstream child had contact with the adults, although the close physical proximity was the same: sitting on the floor for story reading or joining the children at the table in a crouch or small seat for eye-contact.

\section{Practices and Attitudes}

Differences in classroom time, expectations of independence, time erosions and tolerance of interruptions were most noticeable.

The special school spent time on transport, physical care regimes, therapies and slowermoving members of the group which reduced the classroom day to $3 \mathrm{~h} 20 \mathrm{~m}$. Without these constraints the mainstream school had $5 \mathrm{~h} 25 \mathrm{~m}$ available class time. Time erosions depleted the teaching time considerably - late buses and arrivals meant $8 / 10$ children were in class by 9.20 , each new arrival occasioning further distraction.

Pupils on the mainstream site took personal responsibility for moving themselves into, about and from the school and classes unaccompanied and with their own equipment. They did not have the special school's limitation of less physically-able children to help and accompany. The able-bodied special school children had to wait for their slower peers, the whole class moving at their pace.

Teaching activities were frequently interrupted in special school by changes to individual timetables, medical visits to the classroom, withdrawals for therapy and visitors. Parents and non-teaching staff had access to the teacher at all times. The mainstream school had established a practice of non-interruption during teaching time which avoided fragmentation of the lesson and opportunities for children to become distracted or diverted.

The structured mainstream school day adhered to a simpler timetable than the special school, which accommodated a range of individual and special activities. The far wider differentiation of teaching in the special school, to meet exceptional needs of other pupils, affected the sample group considerably. 
The mainstream school's whole group was more homogeneous and meeting their narrower range of needs within a tighter structure was simpler to manage.

The classroom language used at the mainstream school was more sophisticated. The special school laid much emphasis on spoken praise, language was simple and direct allowing for comprehension by the less fluent members of the class, and was often accompanied by signing. Mainstream school language was more challenging, they used the following terms freely:

Maths: take away, subtract, higher than, difference between, minus, total

Science: vitamins, vibrations, flexible

D\&T: recite, recall, consider

Both groups were part of a larger number of children and adults in small working spaces. Both were operating within constraints imposed by their environment - the special school by the exceptional needs of others and the obligation of individual curricula, and the other school by the need to fit into a mainstream timetable with little opportunity to reinforce learning or deliver individual timetables.

The overall impression gained from classroom observation was that:

The mainstream school was structured, straightforward and rigorous

The special school was more fluid, responsive and complex.

\section{Conclusion}

A small-scale systematic investigation of one aspect of educational provision for children with severe learning difficulties indicated that their social development can be better served by inclusive education on a mainstream site. It further noted that differences remain in staff attitudes and practices between the two environments, while curricular and policy issues have been drawing closer together.

This study was limited in considering only one aspect of the wide range of educational services available in both types of school. Special schools offer subjects, therapies, specialist teaching and differentiated approaches to meet the wide variety of needs of their exceptional children as well as the National Curriculum. Constraints on their time, provision and opportunity for learning are more severe than mainstream schools encounter, and unavoidable since they are dictated by the children's learning difficulties. However social development is considered important by staff on both sites, particularly as it translates into educational outcomes.

\section{Discussion}

\section{Discernible Differences in Location}

Personal observation by the researcher had been afforded by teaching in special schools and establishing integration projects with mainstream schools in Oxfordshire and Lancashire LEAs over a period approaching twenty years. Experience had suggested that:

- children working at an academic level below their chronological age were perceived as being less socially mature

- children's socialisation level was assumed to correspond with their academic rather than chronological age

- this immaturity was believed to be engendered by the child's disability rather than the result of school attitudes and practices

- the primary socialisation of children was extended in special schools, thus delaying their secondary socialisation

- the familial atmosphere which this created in special schools was seen as a strength and promoted by staff. It was rarely questioned as a potential drawback to maturity.

Observation of children with similar disabilities educated on mainstream sites indicated that different regimes and expectations existed in pupil-teacher relationships which, combined with peer group role models, had resulted in closer comparisons of socialisation with a narrowing of the gap at Key Stage 4.

Social development is not only linked to educational objectives, it has far-reaching effects in terms of stereotyping pupils with disabilities, projected underachievement, unrealistic goalsetting whether high or low, and eventually impinges on equality of opportunity, selfadvocacy and independence as basic human rights issues.

Warnock (1978) regarded social integration as of sufficient importance to re-locate children with special needs into mainstream schools. The question inevitably arises of what may be lost to such children through re-location. The DFE (1992) audit assessed the quality of education for pupils with special needs removed to ordinary schools where the 'special expertise' 
was no longer available to them as remaining "virtually the same." It noted that the quality of pupils' learning in special schools was adversely affected by lack of pace, assessment and associated response to pupils' individual needs, and "a low level of expectation." This was confirmed by HMI reports on the quality of provision in special schools. ${ }^{3}{ }^{4} \mathrm{~A}$ recent Ofsted report found that up to a third of special schools fail to meet official standards or have serious weaknesses; pupils needed teaching which was intellectually challenging. ${ }^{5}$

Fish (1985) recognised that small special schools "offer many advantages in the personal care of individuals" but balances this with the wider perspective drawn from his OECD work (1992) that "failure to make a distinction between a disability and its handicapping effects... may limit expectation." He goes on to say that a lack of knowledge about relevant goals for those with disabilities may inhibit progress, and locates the issues of post- 16 transition into the earlier years of education. His emphasis is on the development of self-advocacy which "should result in the individual being supported and empowered to make decisions and plan his or her own life." (Fish 1992) The transfer of power from the parent to the teacher and on to the individual is, he admits, difficult to manage where there is a need for considerable physical care. The teacher has dual and conflicting roles of empowerment and care; this causes ambivalence leading to uncertainty in practice which can work against ultimate empowerment of the individual.

Mason (1990) affords education prime position in the human right issues of disabled people, because "it is where we develop our basic attitudes to ourselves (and) inequality in education leaves us disabled people at a great disadvantage." Where provision is focused on the 'condition' rather than the person, the control a disabled child exercises over their own life is reduced and goals are set which are not of their choosing. Learning difficulties are assumed and seen as being caused by the disability, therapies are then imposed to 'improve' it and children segregated from their peers in order to have their special needs attended to. Sadly "they may not be able to make their protests understood and any protests may be seen as symptoms of their disabilities which require more 'treatment'."

Although these issues of self-advocacy and personal choice seem to fit more easily into the
Mason and Rieser (1990) paradigm of an empowered person with a single physical, motor or sensory disability, nevertheless the arguments for basic rights and the removal of barriers in education apply equally to people with more profound or multiple disabilities.

\section{Socialisation as a Single Issue}

There are many indicators shared by mainstream and special schools. Differences which do exist are mostly of degree: the nature and small numbers of children, specialist equipment, high staff ratio and close family atmosphere. This last feature remains one of the hallmarks of special schools and frequently attracts comment.

Recent educational developments at a national level ${ }^{6}$ have brought special and mainstream schools closer in terms of curriculum, funding and special needs expertise. With long-running integration projects, practice and attitude have also tended towards a common vision. New elements of accountability have been extended to special schools, where effectiveness of outcome shares mainstream criteria.

Nevertheless the intensive, child-centred attitudes and practices of special schools continue to be perceived as a predominant strength. If the cherished familial atmosphere of special schools has no negative side then mainstream schools would do well to emulate it. But if there are drawbacks, then special schools need to reflect on the practices and attitudes which bring about this atmosphere. Rather than take it for granted as an unchallenged good, they would need to balance its cost in terms of other educational issues.

\section{Disability as a Social Issue}

Much work has been done by CERI (1988) on the developing socialisation of schoolchildren with disabilities, and its consequences in both the social construct of disability and the outcomes of education as self-definition and independent living. The implications are therefore far-reaching, affecting not only society's view of disability but the disabled individual's view of themselves as part of that society. Söder's (1989) views on the social factors influencing disability, and the personal reflections of Rieser (1988) and Mason (1990) have stressed the importance of equality issues in the classroom. Abberley (1987) sees a concept of oppression arising directly from social attitudes towards

\footnotetext{
3 'Assessment, Recording and Reporting in Special Schools. A report by HMI.' DES 1991

4 'National curriculum and Special Needs. A report by HMI.' DES 1991

${ }^{5}$ From Sunday Times, 24th November 1996 1:9

${ }^{6}$ Educational Act 1981, Education Reform Act 1988, Education (Schools) Act 1992, Dearing Report 1993.
} 
disability, which begin with lowered expectations of the disabled child. Goffman's (1963) seminal work on stigma describes impairment (sic) as an alternative reality requiring different social behaviours, but maintains that these differences are sponsored by insecurity provoked by a disability, not by the disability itself.

Differences from the social norm caused by disability always carry connotations of inferior status; the word itself implies the 'inability' to do and be as others. According to CERI (1988) this creates a circle of disability where the negative effects on a person's self-esteem give rise to a low self-image which invites further differences of reaction. These reactions can be forked; either a rejection of the disabled person's full human rights, or patronising kindness. A third reaction, that of controlling, is also possible.

Initial diagnosis or awareness of difference from the norm comes via non-conformity with normal communication patterns. That these are caused not by the disability itself but by unsuccessful socialisation has formed the basis for many OECD/CERI studies, among others (Rees \& Emerson, 1984; Finkelstein, 1980). Segregated children have very different experiences of the usual life sequences and events, largely through lack of opportunity; they are rarely offered the chance to take risks and learn through experience. The element of control is not far away when life experiences have pre-selected routes.

\section{Secondary Socialisation}

These studies have stressed the importance of the developmental stage of secondary socialisation which can be delayed by confusion of roles between home and school, and the relationship developed between children with disabilities and their professional carers. CERI studies suggest that for most children 'home and parent' is different from 'school and teacher', but children with disabilities often confuse these roles or delay their internalised definition of them. Nursery and reception class children sometimes confuse these roles; it is a process which must be learned. It is desirable and necessary that children learn many levels of relationship of increasing complexity and distance as they mature into adult life. If schools assume that children with handicaps mature more slowly than their peers, they are stereotyping children and instituting a societal division which will reduce expectation and affect the ultimate educational outcomes. More seriously, if teachers believe that the cause of social delay lies in the disability itself, rather than the environment in which the child is placed, they are unlikely to reflect on how appropriate teaching practices may decrease the child's difficulties.

The issue of social maturity impinges very strongly on the inclusive education debate and the placing of pupils in integrated settings. Having fed into the Warnock Committee's (1978) tenets on non-segregated education, social development remains at the core of the debate on inclusive education for children with learning difficulties.

If such a division between special and mainstream schools exists, differences will be detectable and quantifiable in terms of language and behaviour and will be embedded both in attitudes and practices. What can be detected through a micro study of a fairly typical model of provision could have wider implications for other special schools and their linked mainstream partners.

\section{Acknowledgements}

Sponsored by the Teacher Training Agency's Teacher-Researcher Grants Scheme.

Note: This article is adapted from a paper presented by the authors at the British Educational Research Association Conference at Lancaster University and the European Conference for Educational Research in Frankfurt, 1997.

\section{Correspondence}

Denise Dew-Hughes \& Dr. Sonia Blandford, Oxford Brookes University, School of Education, Wheatley, Oxon. OX33 1HX. U.K. 


\section{References}

Abberly, P. (1987). The concept of oppression and the development of a social theory of disability.

Disability, Handicap and Society, 2 (1), 5-9.

Booth, T., Swann, W., Masterson, M. \& Potts, P. (1992). Policies for Diversity in Education. Learning for All 2. Routledge, London \& New York in assoc. with Open University, Milton Keynes.

CERI (Centre for Educational Research and Innovation) (1988). Disabled Youth. The Right to Adult Status. (1981). Integration in the School. (1986). Young People with Handicaps. The Road to Adulthood. OECD Paris.

Dew-Hughes, D. M. (1983). The Marlborough / Ormerod Project.' CSIE Factsheet. (1984). Like Other Children. Mediscreen film for Channel 4 TV.

DFE Audit Commission, (1992). Getting in on the Act. Provision for Pupils with SEN: The National Picture. HMSO London.

Finkelstein, F. (1980). Attitudes and Disabled People, World Rehabilitation Fund Monograph, No. 5 p.33.

Fish, J. (1992). An International Perspective on Transition. In Booth, T., Swann, W., Masterson, M. \& Potts, P. (Eds.). Policies for Diversity in Education. Learning for All 2. Routledge, London \& New

York in assoc. with Open University, Milton Keynes.

Fish, J. (1985). Educational Opportunities for All. ILEA.

Goffman, E. (1963). Notes on the Management of Spoiled Identity, p.6 Stigma. Prentice Hall Inc. Englewood Cliffs. New Jersey.

Mason, M. (1992). The Integration Alliance. Background and Manifesto. In Booth, T., Swann, W., Masterson, M. \& Potts, P. (Eds.). Policies for Diversity in Education. Learning for All 2. Routledge, London \& New York in assoc. with Open University, Milton Keynes.

Mason, M. \& Rieser, R. (Eds.) (1990). Disability Equality in the Classroom: A Human Rights Issue. Disability Equality in Education. PIP London.

Rees, S. \& Emerson, A. (1984). Reports and Proceedings, No. 37 Disabled Children, Disabling Practices.

Rieser, R. (1988). Struggling to overcome discrimination. The Teacher, 14, March p.13.

Söder, M. (1989). Disability as a social construct: the labelling approach revisited. European Journal of Special Needs Education, 4 (2), 117-29.

Southgate, T. (1992). Finding a New Place: Changes in Role at Ormerod School. In Booth, T., Swann, W., Masterson, M., \& Potts, P. (Eds.). Policies for Diversity in Education. Learning for All 2.

Routledge, London \& New York in assoc. with Open University, Milton Keynes.

Warnock, M. (1978). Special Educational Needs. London: HMSO.

Wilson, D. (1993). Perceptions of Integration by the Decision Makers. OxSpec Occasional Papers, No 6 .

\section{Further reading}

This study is informed by issues of equality of opportunity and of racial and gender stereotyping leading to reduced expectation of achievement which have implications for comparable issues of disability stereotyping. Wider reading suggests the following texts have relevance:

Barton, L. (1986). The politics of special educational needs. Disability, Handicap and Society, 1, (3). Blair, M. (1995). Race, class and gender in school research. In Blair et al (Eds.) Debates and Issues in Feminist Research and Pedagogy. Clevedon: Intellectual Matters.

Booth, T. (1987). Labels and their consequences. In Lane, D \& Stratford, B (Eds.) Current Approaches to Downs Syndrome. London: Cassell.

Connolly, P. (1995). Racism, masculine peer-group relations and the schooling of African/Caribbean infant boys. British Journal of Sociology of Education, 16, (1). 
Donnelan, C. (19??). Disabilities and Discrimination. Issues for the Nineties. Vol 17. Cambridge. Lea, S. J. (1988). Mental retardation, Social construction or clinical reality? Disability, Handicap and Society, 1, (3).

Morris, J. (1992). Personal and political: A feminist perspective on researching physical disability. Disability, Handicap and Society, 7, (2), 157-166.

Tomlinson, S. The Social Construct of the ESN(M) Child. Special Education. Undated reprint. 